$$
\begin{array}{r}
\text { DE CAC } \\
\text { PEDRAS MOLES E OUT } \\
\text { MARCAS: PERCURSOS DE } \\
\text { ARQUEOLO } \\
\text { NÃO-QUALIFIC }
\end{array}
$$




\section{DE CACOS, PEDRAS MOLES E OUTRAS MARCAS: PERCURSOS DE UMA ARQUEOLOGIA NÃO-QUALIFICADA}

\section{MARIANA PETRY CABRAL}

INSTITUTO DE PESQUisas CiENTÍFICAS E TECNOLÓGICAS DO ESTADO DO AMAPÁ, MACAPÁ/AP, BRASIL 


\title{
DE CACOS, PEDRAS MOLES E OUTRAS MARCAS: PERCUR- SOS DE UMA ARQUEOLOGIA NÃO-QUALIFICADA
}

\section{Resumo}

Partindo do princípio de que arqueologia é um modo de construir narrativas a partir dos vestígios materiais que apontam para outros tempos, sigo algumas proposições - na arqueologia e na antropologia - que sugerem, apesar do indiscutível fardo modernista da ciência, que é possível pensar (e, portanto, praticar) modos desta construção de conhecimento que não se atêm ao modelo modernista. A partir da posição de sujeito moderno, formada no seio da epistemologia científica, aventuro-me a refletir sobre estas possibilidades com base em uma experiência em andamento junto a um grupo indígena no norte amazônico. Fugindo dos qualitativos costumeiramente empregados para localizar práticas arqueológicas realizadas com populações atuais, argumento que esta qualificação é mais uma maneira de domesticar outros modos de conhecimento dentro da Arqueologia (com A maiúsculo, já supostamente universal).

Palavras-chave: Modos de conhecer, práticas arqueológicas, diálogos

OF SHERDS, SOFT STONES, AND OTHER VESTIGES: PATHS OF AN UNQUALIFIED ARCHEOLOGY

\begin{abstract}
Assuming that archeology is a way to construct narratives from the material traces from other times, I follow some propositions - in archeology and anthropology - which suggests that, despite the undeniable burden of modernist science, we can consider (and therefore practice) modes of knowledge building that does not cling to the modernist model. From the modern subject position, however, formed within scientific epistemology, I venture to think about these possibilities based on an experiment in progress with an indigenous group in the northern Amazon. Fleeing the qualitatives customarily employed for locating archaeological practices conducted along the existing populations, I argue that this qualification is more a way of domesticating other modes of knowledge within archeology (with a capital A, as supposedly universal).

Keywords: Ways of knowing, archaeological practices, dialogues
\end{abstract}




\section{À PROPOS DES TESSONS, DES PIERRES MOLLES ETD'AUTRES MARQUES: PARCOURS D'UNE ARCHÉOLOGIE NON-QUALI- FIÉE}

\section{Résumé}

En partant du principe que l'archéologie est un mode de construction de récits à partir des vestiges matériels qui touchent d'autres époques, je suis certaines propositions - d'archéologie et d'anthropologie - qui suggèrent que - malgré l'indiscutable fardeau moderniste de la science - il est possible de penser (et donc de pratiquer) des modes de cette construction de connaissance qui ne se limitent pas au modèle moderniste. Néanmoins, en tant que sujet moderne, formé au sein de l'épistémologie scientifique, je m'aventure à mener une réflexion sur ces possibilités en me basant sur une expérience en cours menée avec un groupe d'indiens du nord de l'Amazonie. Fuyant les qualificatifs habituellement employés pour situer des pratiques archéologiques réalisées avec des populations vivantes, j'argumente que cette qualification est davantage une manière de domestiquer d'autres modes de connaissance au sein de l'Archéologie (avec un A majuscule, étant supposément universelle).

Mots-clés: Modes de connaissance - Pratiques archéologiques - dialogues

Endereço da autora para correspondência: Instituto de Pesquisas Científicas e Tecnológicas do Estado do Amapá, Av. Feliciano Coelho, 1509, Trem, Macapá/AP, CEP 68901-025. E-mail: nanacabra175@gmail.com 


\section{INTRODUÇÃO}

Há alguns anos, fui convidada para iniciar uma conversa com o povo indígena Wajãpi sobre uma pesquisa de arqueologia na terra indígena, a convite da antropóloga Dominique Tilkin Gallois, que mantém uma relação de longa data com este povo. Os Wajãpi são um grupo do tronco tupi-guarani que habita hoje regiões do interior das Guianas. Os antropólogos fazem distinção entre o grupo que vive na Guiana Francesa e o grupo que vive no Estado do Amapá (Grenand \& Grenand 2002, Grenand, Gallois \& Grenand 2009). É com este último que tenho desenvolvido a pesquisa que provocou as reflexões apresentadas neste texto.

$\mathrm{O}$ interesse manifesto na pesquisa de arqueologia pelos Wajãpi parece ter iniciado da curiosidade sobre alguns cacos de cerâmica que não lhes pareciam familiares. Em uma região do limite Norte da Terra Indígena Wajãpi (TIW), um fragmento de cerâmica com forma de uma pequena cabeça antropomorfa, despertou interesse de Kasiripinã Wajãpi, liderança importante e bastante ativa, que acompanhou e lutou pelo longo processo de demarcação e homologação da TIW, finalizado em 1996 (Gallois 2011 discorre sobre a história deste processo).

A curiosidade sobre este pequeno fragmento despertou um interesse em saber quem o havia feito, já que para os Wajãpi aquilo claramente não era de seus avós, tamõkõ. Ao indagarem a antropóloga Dominique Tilkin Gallois, ela respondeu que havia um tipo de pesquisador que poderia ajudá-los: os arqueólogos. Foi assim que fui conhecê-los, introduzida como a especialista sobre um determinado tipo de conhecimento.

É verdade que, em um primeiro momento, da minha parte, a pesquisa tinha um foco mais forte no interesse sobre a arqueologia de áreas florestadas no Amapá (amplamente desconhecida), porém, a interação entre nós foi produzindo outros interesses. Não demorou para que eu percebesse que os conhecimentos dos Wajãpi tinham um fértil potencial para desestabilizar as bases do meu conhecimento científico, levando-me a refletir não apenas sobre a prática científica, mas, essencialmente, sobre o impacto desta sobre grupos que não partilham das mesmas fundações epistemológicas (Nicholas 2005 apresenta uma reflexão sobre os impactos negativos destes encontros).

Para além de uma percepção individual, o amadurecimento da pesquisa de arqueologia com os Wajãpi se deu pelas possibilidades de diálogo que me foram postas. As vivências, durante oficinas de formação da turma de pesquisadores wajãpi, com a antropóloga Dominique T. Gallois e outros assessores do Programa Wajãpi ${ }^{1}$, introduziram-me em um ambiente de diálogo com os Wajãpi em que as diferenças entre sistemas de conhecimento eram (e seguem) aparentes.

Em um texto recente sobre o processo de formação de pesquisadores Wajãpi, isto é explicitado:

"o programa de formação procura priorizar questões relacionadas à diversidade das formas de construção e de transmissão do conhecimento. Em especial, busca-se des- 
tacar as diferenças entre as 'lógicas' ou teorias subjacentes às classificações e explicações do pensamento acadêmico-científico ocidental, de um lado, e aquelas que sustentam as classificações e explicações do pensamento wajãpi, de outro lado" (Gallois et al. 2013:72).

Tal situação cria um ambiente muito proveitoso para exercícios de comunicação entre sistemas de conhecimento distintos. De fato, a base de construção desta pesquisa repousa na ideia de que é possível criar interações entre estes sistemas de conhecimento (arqueologia, o conhecimento nativo e a antropologia) de forma a produzir pontes entre eles, instigando comparações e traduções, justamente porque as lógicas sustentando os conhecimentos são distintas. Como os próprios pesquisadores wajãpi afirmam sobre a experiência de formação:

"Nas oficinas [de formação de pesquisadores] fazemos atividades para aprender a sistematizar os conhecimentos, a fazer explicações detalhadas e explicações gerais, aprendemos a fazer interpretações e reflexões e a fazer aparecer as teorias do pensamento e da prática dos Wajãpi. Nós também aprendemos a fazer tradução. Nós aprendemos que não podemos traduzir uma palavra de uma língua com uma palavra de outra língua, porque por trás das palavras existem ideias diferentes. Aprendemos que para traduzir a lógica wajãpi para os não índios, precisamos aprender a fazer explicações bem detalhadas" (Pesquisadores Wajãpi 2012).

A partir desta experiência de diálogo e informada por discussões presentes na bibliografia, tanto da arqueologia quanto da antropologia, comecei a perceber a arqueologia como uma prática de sentido, em que vestígios materiais são manipulados na construção de narrativas sobre outros tempos. Seguindo esta linha, particularmente instigada por uma proposição de Roy Wagner, porém transposta para a arqueologia, coloquei a questão de pensar os Wajãpi como arqueólogos. Wagner (2010 [1975]), ao propor o que chama de uma antropologia reversa, altera os pólos de autoridade na produção de conhecimento, afirmando que os nativos também são antropólogos.

Desta forma, partindo do princípio de que arqueologia é um modo de construir narrativas a partir dos vestígios materiais, busco seguir algumas proposições que sugerem, apesar do indiscutível fardo modernista da ciência, que é possível pensar (e, portanto, praticar) modos desta construção de conhecimento que não se retêm ao modelo modernista. Fugindo dos qualitativos costumeiramente empregados para localizar práticas arqueológicas realizadas com populações vivas (de etnoarqueologia à arqueologia pública), argumento que esta qualificação é mais uma maneira de domesticar outros modos de conhecimento dentro da Arqueologia (com A maiúsculo, já que supostamente universal).

No momento em que classificamos estas práticas dentro de rótulos qualificados, reforçamos hierarquias sobre a autoridade do conhecimento. Como recorda Françoise Grenand (2009:242), questionando justamente estas hierarquias: "Lembramo-nos en- 
tão do gracejo que Haudricourt lançava algumas vezes nas suas aulas: 'A botânica é a etnobotânica dos botânicos"” A arqueologia é a etnoarqueologia dos arqueólogos, porém, justamente pela eficácia do aparato científico mobilizado para autorizar este conhecimento (sensu Latour 1994), nem sempre se reflete sobre isso.

\section{O CONTEXTO DE DIÁLOGOS}

Antes de ampliar esta discussão sobre modos de praticar arqueologia, volto-me para uma contextualização deste local de onde as reflexões emergiram. Como apontado mais acima, a construção de um projeto de pesquisa de arqueologia na Terra Indígena Wajãpi ocorreu através de diálogos tanto com os Wajãpi quanto com a antropóloga Dominique Gallois e outros assessores envolvidos no Programa Wajãpi.

É importante ressaltar o contexto recente do povo wajãpi. Ainda que eles vivam hoje em uma situação privilegiada no contexto indígena brasileiro, com uma terra grande, demarcada e homologada, seu histórico de luta pela autodeterminação é antigo. Desde a década de 1990, com apoio de antropólogos, da agência oficial e de ONGs, eles têm atuado no seu fortalecimento cultural (Gallois 2011).

Essas ações de fortalecimento e valorização internos contribuíram para a elaboração da proposta de inscrição do sistema gráfico kusiwarã no Livro de Registro das Formas de Expressão do Instituto do Patrimônio Histórico e Artístico Nacional (IPHAN), que foi certificada em 2002, tornando-se Patrimônio Cultural do Brasil ${ }^{2}$ (IPHAN 2002). Ainda em 2002, os Wajãpi enviaram a candidatura à seleção da UNESCO de Patrimônio Oral e Imaterial da Humanidade, a qual foi aceita em 2003, e inscrita na Lista Representativa do Patrimônio Cultural Imaterial da $\mathrm{Hu}-$ manidade em 2008 (UNESCO 2012).

Estas duas inscrições do patrimônio cultural wajãpi tiveram desdobramentos importantes, como o Plano de Salvaguarda do Patrimônio Imaterial Wajãpi, voltado para a revitalização das formas de expressão gráficas e orais (Gallois 2006, 2012) reflete sobre este recente processo). Uma das ações de fortalecimento cultural é a Formação de Pesquisadores Wajãpi, coordenado pela antropóloga Dominique Tilkin Gallois (Gallois et al. 2013) tratam desta formação). Como destacado em um texto recente, este processo de patrimonialização no qual os Wajãpi estão inseridos requer reflexões constantes em função dos "riscos" deste tipo de ação na transformação dos modos de produção e uso dos conhecimentos:

"considerando a complexidade de um trabalho deste tipo [Plano de Ação para valorização interna das formas de expressão oral] e para evitar equívocos freqüentes em ações de promoção cultural - especialmente quando configuradas como ações voltadas ao 'resgate' (de supostos conteúdos culturais) ou à 'visibilidade' (da cultura como espetáculo) - optou-se por um programa de longo prazo, que poderia ser desenvolvido com apoio sucessivo de diversas instituições e projetos." (Gallois et al. 2013: 55) 
Se eu considero hoje que é viável praticar um diálogo com os Wajãpi sobre as maneiras de construir narrativas a partir de vestígios materiais, ou seja, modos de praticar arqueologia, é porque eles têm praticado exercícios de tradução nos seus próprios termos. A formação que jovens pesquisadores $\mathrm{e}$ jovens professores recebem em oficinas e estágios sobre várias temáticas criam um contexto muito interessante de pesquisa conjunta.

É dentro deste contexto que eu me apóio na noção de simetria para buscar dissolver as hierarquias que costumeiramente se impõem no contato entre sistemas de conhecimento científicos e tradicionais. Acompanhando reflexões de antropólogos como Eduardo Viveiros de Castro e Roy Wagner, o exercício em jogo é colocar estas diversas lógicas em um mesmo patamar, simetrizar conceitos, teorias sobre o real. Nas palavras de Viveiros de Castro (2002), "levar a sério" o que o outro diz, entender o sistema de conhecimento do outro como um sistema de conhecimento completo. Esta pesquisa, portanto, é pensada como a construção de uma rede de relações, em que os diferentes agentes podem ser vistos como os nódulos desta rede, demandando um constante nivelamento entre eles (Latour 2005).

Como parte deste processo de fortalecimento cultural que os Wajãpi têm praticado nas últimas décadas, a pesquisa de arqueologia busca contribuir para a sistematização de saberes e conhecimentos wajãpi sobre a história de seu território. Esta história, no entanto, não se limita à categoria científica ocidental, pelo contrário, ela está voltada para as concepções nativas deste processo, logo, abarca a cosmogênese Wajãpi. Diferente das discussões já avançadas por Gallois (1988, 1994), o interesse na história para a pesquisa de arqueologia está pousado sobre os vestígios materiais. É a articulação entre conhecimentos e vestígios materiais, na elaboração de narrativas para explicá-los, que cria a possibilidade de se praticar arqueologia.

Reconhecer o modo Wajãpi de ver os produtos dos diversos agentes que povoam o mundo como fatos materiais completos abre a possibilidade de existência de uma outra arqueologia. No mesmo sentido da etno-historiografia Wajãpi proposta por Gallois (1994:12), torna-se possível estudar as formas Wajãpi de manipulação dos fatos materiais para administrar sua relação com o mundo e com os outros seres que o habitam. Enquanto uma arqueologia convencional estaria atenta apenas às marcas (que consideramos válidas) de ação humana, aqui há a possibilidade de outras marcas também contarem história, ou melhor, de outros agentes usarem estas e outras marcas para contar suas próprias histórias.

\section{ARQUEOLOGIA: ARQUEOLOGIAS}

$\mathrm{Na}$ última década, as discussões sobre o impacto dos encontros entre sistemas de conhecimentos distintos em pesquisas arqueológicas ganharam um fôlego intenso, com uma farta produção bibliográfica fortemente embasada na noção de descolonização. A relevância da posição de vários coletivos 
de não-arqueólogos, que se viam mais e mais entrelaçados com a arqueologia, trouxe uma ampla gama de experiências de envolvimentos - em diferentes graus - com populações vivas, as quais de fato povoam a pesquisa arqueológica moderna desde seus primórdios, porém, apenas recentemente reconhecidas como agentes ativos nestes processos.

Volumes dedicados à arqueologia realizada para, com e por povos indígenas e comunidades de descendentes marcaram fortemente os debates, ressaltando-se modos de ampliar e cultivar colaborações e participações de diferentes coletivos. Cito como exemplo os trabalhos de Smith \& Wobst (2005), Castañeda \& Matthews (2008), Colwell-Chanthaphonh \& Fergunson (2008), Hamilakis \& Anagnostopoulos (2009), Mortensen \& Hollowell (2009), Bruchac, Hart \& Wobst (2010), Phillips \& Allen (2010) e no contexto da América Latina ressalto a publicação de Gnecco \& Rocabado (2010).

Também no Brasil, experiências de práticas públicas e colaborativas têm promovido discussões relevantes não apenas para o contexto acadêmico, mas também para os contextos sociais em que estes coletivos estão inseridos. Destaco os trabalhos de Green, Green \& Neves (2003), Eremites de Oliveira \& Pereira (2010), Silva (2011), Silva, Bespalez \& Stucchi (2011), Bezerra (2011, 2013) e o recente volume temático da Revista de Arqueologia editado por Bueno \& Machado (2013).

Em meio às discussões levantadas, a crítica ao papel colonialista do empre- endimento científico recebeu um espaço privilegiado (Gonzalo 2006, Haber \& Gnecco 2007, Gnecco 2009, 2012), justamente pela observação de que o silenciamento de outros coletivos na construção do conhecimento arqueológico é uma maneira de manter a supremacia de cientistas (no caso, arqueólogos) na relação com os outros. Tal situação não apenas reitera o poder da ciência moderna ocidental, como desqualifica outros conhecimentos. Como afirma Alejandro Haber (2009:3): "The idea of one version of history as universally valid implies its validation against local histories, the imposition of one way of understanding history, our relationship with the past, and 'humanity' as self-projected towards the future".

É neste sentido que Cristóbal Gnecco, talvez um dos críticos mais contundentes à prática arqueológica moderna e ocidental, desmonta a própria qualificação destas arqueologias como "alternativas" ou "indígenas":

"Se o termo indígena implica manter uma postura contra a modernidade (ou, pelo menos, a vontade de ser uma alternativa para a modernidade), onde fica a maior parte de seu poder político e de suas promessas utópicas, ele não pode ser um adjetivo à arqueologia (uma disciplina moderna praticada por indígenas), mas um substantivo que implica cosmologias alternativas em seus próprios termos. As arqueologias alternativas que mantenham os princípios básicos da arqueologia reforçam a cosmologia ocidental" (Gnecco 2012:16). 
Ora, ainda que o uso destes qualitativos possa ser entendido como uma classificação necessária para separar práticas arqueológicas "normais" -no sentido de "ciência normal" cunhado por Thomas Kuhn (2003) - de práticas que visam questioná-las, concordo com Gnecco: adjetivar estas práticas tende a reforçar o pólo de poder na Arqueologia (com maiúscula, porque supostamente universal). Enquanto alguns arqueólogos, que seguem trabalhando sem interação com populações vivas, classificam suas pesquisas como "arqueologia", aqueles que se aventuram a buscar diálogos com outros coletivos humanos fazem sempre arqueologias adjetivadas (públicas, indígenas, participativas, colaborativas, etc). Adjetivar, neste contexto, é uma forma de restringir, por um lado, e uma forma de domesticar, por outro. Ao que parece, são arqueologias incompletas, arqueologias menores. É preciso se perguntar, como aponta Gnecco (2012), sobre a necessidade de se qualificar estas arqueologias.

Considerando que a Arqueologia é uma disciplina moderna ocidental, que se estruturou e se fortaleceu dentro (e através) de um quadro autoritário, como todas as ciências, é também aí que encontra seu atual local de conflito. Será possível - ou mesmo viável - praticar uma arqueologia fora deste quadro? (Gonzalo 2006, Haber \& Gnecco 2007).

Voltando à proposição de Roy Wagner, transposta para a arqueologia, todos são arqueólogos, logo, fazer arqueologia deixa de ser uma prerrogativa daqueles treinados nas normas cientí- ficas. Parece ser neste mesmo sentido que Yannis Hamilakis defende a existência de arqueologias pré-modernas na Grécia, tomando como exemplo a história de uma peça arqueológica que foi levada para a Inglaterra no século XIX, apesar da população local opor-se. Para Hamilakis (2008), a forma como a população lidava com vestígios antigos aponta para uma arqueologia:

"The people of Eleusis were practising their own archaeology: they had noticed the statue, they had exhibited it very close to its original context, they created a discourse around it which was based on its sculptural details such as the representations of the ears of corn, and they venerated it and dedicated to her heaps of dung, as the most appropriate substance for a deity that, like dung, guarantees the fertility of their fields". (Hamilakis 2008:5)

Da mesma forma que estas pessoas, o referido autor ressalta que estes "discursos e práticas [estão] relacionadas às coisas antigas" (Hamilakis 2008:4) e que existem em todos os lugares, entre todos os grupos. A Arqueologia, como disciplina moderna ocidental é apenas mais um modo de criar relações entre vestígios materiais e, nas palavras de Gnecco (2012:18), a "história como experiência vivida".

Ao abraçar esta perspectiva sobre a potencialidade da existência de arqueologias fora do marco científico, não estou propondo que exista uma Arqueologia universal. Pelo contrário, é justamente a crítica a esta ideia que permite a existência de outras arqueologias ou "outros mundos a partir da arqueologia: outras sociedades, outras temporalida- 
des, outras formas de aglutinação, outras formas de ser" (Gnecco 2008:21).

\section{DE CACOS, PEDRAS MOLES E OU- TRAS MARCAS}

Quando realizei minha primeira viagem com os Wajãpi, rumo a uma das aldeias mais distantes, no limite norte da terra indígena, deparei-me certo dia com vários amoladores sobre as rochas na beira de um rio. O que eu vi, no entanto, não foi o mesmo que os Wajãpi viram. Ou melhor, penso que eu e eles vimos as mesmas marcas sobre as rochas, porém, para além de ver, nós entendemos as marcas de maneiras diferentes ${ }^{3}$.

Enquanto eu manipulava meu aprendizado sobre vestígios arqueológicos, que tem nos amoladores de beira de rio uma expressão bastante comum, os Wajãpi manipulavam outro conjunto de saberes. As marcas nas pedras eram vestígios de um tempo primordial, quando as pedras ainda eram moles e Janejarã (o herói criador) ainda andava nesta terra, deixando suas pegadas e as marcas onde havia sentado ${ }^{4}$. Este evento tornou evidente as diferenças entre os regimes de conhecimento que eu e eles estávamos usando. Ainda que a base material fosse a mesma, os conhecimentos eram distintos.

Mas este foi só o começo da pesquisa.

Conforme novas viagens aconteciam e mais vivência eu ganhava na interação com os Wajãpi, comecei a perceber que naquelas florestas por onde caminhávamos por vários dias havia muito mais marcas de acontecimentos do passado do que eu jamais suporia. Enquanto eu e eles estávamos interpretando as mesmas marcas sob perspectivas de $\mathrm{CO}^{-}$ nhecimento distintas, parecia que havia uma base comum entre nossas arqueologias. Ainda que informados por sistemas de conhecimento divergentes, eu pensava que os vestígios eram os mesmos.

Ledo engano. Logo me foi ensinado que as grandes áreas de taboca (uma espécie de bambu) em meio à floresta eram plantações; que o grande angelim (uma árvore de madeira dura) era a casa de um dono (ijarâ); que os finos assobios antes do amanhecer eram de jurupari; que as cores dos pássaros eram suas pinturas na festa primordial; que o peixe pacu era o pão de mandioca (beiju) do sucuriju; e que até o habitat de alguns animais era resultado da queda de uma escada por onde eles tentavam seguir o criador Janejarã quando este subiu. Obviamente, o mundo que eles viam era absolutamente distinto do meu. Se, em alguns casos, nossas marcas do passado coincidiam (como àquelas nas pedras ou os cacos de cerâmica), os acervos que manipulávamos eram bastante divergentes.

Em uma etnografia recente sobre os modos de conhecer dos Wajãpi, particularmente focada nos saberes relativos às plantas, Joana Cabral de Oliveira (2012b) compara os modos de conhecer dos Wajãpi e de cientistas, em especial botânicos, ressaltando o distanciamento de base entre eles:

"Ao percorrermos alguns meandros da produção científica podemos ver muitas outras aproximações, como $\mathrm{o}$ interesse e o cuidado dedicados 
ao sensível evidentes na taxonomia botânica. Todavia tal atenção não é tratada da mesma maneira devido ao status que a experiência e o sensível ocupam nesses dois regimes de conhecimento. A ciência intenta criar índices quantitativos e universais, enquanto os Wajãpi insistem na elaboração de índices minuciosamente qualitativos, e nos apresentam uma lógica de planos múltiplos - avessa à universalização e a homogeneização do conhecimento" (Oliveira 2012b: 248).

Como já sugerido por Viveiros de Castro (2002), enquanto o conhecimento moderno ocidental tem por base a objetivação (ou a dessubjetivação), o modelo ameríndio é o oposto: para conhecer é preciso subjetivar, é preciso criar relações entre sujeitos.

A etnografia elaborada por Oliveira (2012a, 2012b), bem como reflexões recentes de Gallois (2012), apontam para algumas questões muito pertinentes para pensar os modos de conhecer dos Wajãpi no contexto de práticas arqueológicas. A aferição de autoridade está sempre relacionada a uma experiência de um sujeito, que foi capaz de contá-la a outros, criando uma rede de transmissão. Ao analisar experiências que pesquisadores e professores Wajãpi estão elaborando no processo recente de construção de um coletivo de todos Wajãpi (já que tradicionalmente eles estão separados em parcialidades - wana-kô) e na apropriação de novos conceitos (como propriedade intelectual), Gallois destaca um desencontro entre gerações:

"A leitura dessas explicações [sobre as regras de uso do kusiwarã] para alguns anciões e chefes de aldeia gerou muita polêmica em torno de dois problemas: os mais velhos questionaram o modo como teria sido transmitida a fonte de experiência, que é essencial para a validação de relatos a respeito da aquisição de saberes, especialmente em encontros entre humanos e não-humanos; além disso, questionaram a intenção dos donos de ceder seus conhecimentos aos humanos. $[\ldots]$

Quando ouviram os diálogos imaginados pelos jovens, os velhos exclamaram: 'Errado! Esses diálogos não ocorreram, nunca ouvimos falar deles, não foram reportados pelos nossos avôs'. Se a forma discursiva era aceitável, encenando um encontro, faltava algo essencial, que é a repetição, a difusão dessa experiência. Esses diálogos, se tivessem ocorrido, teriam sito citados em narrações dos avôs, dos pais. 'Nunca ouvimos isso', diziam os mais velhos. A trajetória da transmissão não podendo ser explicitada, não há convicção a respeito da experiência que o relato reporta." (Gallois 2012:33-34 - grifos no original).

Como destacado por Oliveira (2012a), em referência à perspectiva de Latour sobre a ciência, o conhecimento Wajãpi requer a teia de relações que o produziu, enquanto o modo científico esforça-se em apagá-la.

Ao pensar nestas reflexões sobre os modos de conhecer deste povo, observo que os mecanismos em uso na construção das narrativas assentadas nos vestígios materiais também seguem estes princípios. É necessária uma rede de relações construídas para 
permitir que uma explicação apareça. Os vestígios materiais que podem ser encontrados no mundo não estão previamente explicados, ou melhor, não estão previamente tecidos em explicações. Ao encontrá-los, quando se tornam aparentes, é que a tecedura tem início. Não existe, por exemplo, uma relação direta entre os cacos de cerâmica e um ancestral, a relação que existe precisa ser construída, a partir de uma base de conhecimento disponível.

Ao caminhar com os Wajãpi por diferentes regiões de sua terra, tive a oportunidade de acompanhar o processo de elaboração destas explicações. Da mesma forma como Oliveira, em um trabalho anterior, indicava que as classificações manipuladas pelos Wajãpi sobre as plantas estão profundamente entrelaçadas às relações sociais (Oliveira 2006), fui percebendo que as explicações sobre os vestígios também estavam. Os jovens remetem-se aos velhos para consultar sobre um novo vestígio encontrado: uma explicação detalhada requer uma troca entre sujeitos. Não basta encontrar vestígios, é preciso entrelaçá-los com saberes e com as pessoas.

Por exemplo: os potes cerâmicos inteiros que estão agora guardados na aldeia Jiruruwyry, no limite oeste da TIW, não existem como vestígios isolados, eles são o resultado da história de Marãte (um dos pesquisadores) correndo atrás de um macaco coatá. São também o resultado da conversa de Marãte com seu pai, que localizou a área do achado com uma antiga aldeia, Waipyó. São ainda a costura destas informações com uma observação cuidadosa do local, que tinha marcas de ser uma antiga aldeia. Os potes não são um vestígio arqueológico no sentido usual da Arqueologia, ou seja, não são vestígios arqueológicos "puros" ou "purificados" - nos termos de Latour (1994). De fato, para os Wajãpi, parece que eles não teriam o mesmo interesse se não houvesse justamente esse emaranhado que conecta o vestígio, com saberes, com lugares, com pessoas.

\section{CONCLUSÃO: LONGE DE CONSEN- sos}

Ao longo destes anos, conforme a pesquisa de arqueologia foi sendo produzida e a curiosidade sobre este conhecimento específico que eu detinha foi angariando pessoas, os espaços de oficinas de formação de pesquisadores abriram várias oportunidades para o exercício de troca de conhecimento. Em uma entrevista realizada há alguns anos, a antropóloga Dominique Tilkin Gallois (2001:5) resumiu de maneira muito clara esta opção pelo diálogo de saberes: "Eu sempre digo que temos que promover o encontro de conhecimentos porque surge daí uma reflexão intelectual sobre o outro".

Para mim, foi bastante emblemático, a partir desta "reflexão intelectual sobre o outro", o desenrolar sobre minha introdução de um conceito da arqueologia. Em uma das oficinas, eu apresentei a ideia de estratigrafia, em especial porque os planos de uma escavação a ser realizada haviam criado muita expectativa sobre como os arqueólogos sabiam sobre as coisas dos antigos. 
O princípio de estratigrafia, da passagem do tempo que soterra o passado, pareceu claro para a turma. Eles conhecem vários lugares em que os cacos vieram à superfície em função de quedas de árvores, quando as raízes trazem para cima a terra mais do fundo. Surgiram dúvidas sobre essa acumulação constante e se era possível calcular o tempo a partir da profundidade. Enfim, era uma ideia nova.

Neste mesmo dia, para minha surpresa, um dos participantes usou a ideia de estratigrafia para falar sobre o conhecimento. Em função da pressão cada vez mais forte de missionários, houve uma discussão sobre o efeito dos evangélicos sobre o conhecimento Wajãpi. Aikyry, professor e jovem liderança, usou uma imagem de estratigrafia para afirmar que o conhecimento Wajãpi estava no fundo, soterrado por outros conhecimentos. Era preciso escavar como na arqueologia para chegar até ele. Foi uma imagem forte que acalmou a discussão.

Passados cinco meses, eu reencontro Aikyry em outra oficina, na terra indígena. Preocupado, ele me contou que teve dificuldades para explicar para os velhos a estratigrafia. Ele queria explicar para eles como os arqueólogos sabem que aquilo que está no fundo da terra é antigo. No entanto, para os velhos, como ele me explicou, o antigo não podia estar no fundo. Para me explicar, ele fez uso da imagem de uma árvore: começa com uma pontinha, um talo, uma folha, e vai crescendo, vai subindo a folha: a parte de cima da árvore é a mais antiga.
Ora, essa dificuldade de tradução colocava em choque diferentes noções de temporalidade. O tempo, nesta discussão, como é óbvio no princípio de estratigrafia, implicava noções de espaço. O que me parecia um princípio natural (o que está mais ao fundo é mais antigo), era claramente uma formulação equivocada para os velhos Wajãpi. É claro que eles reconhecem a presença de coisas dos antigos debaixo da terra, encontrando estes vestígios com certa facilidade nas roças. $\mathrm{O}$ que eles parecem discordar é sobre a relação entre espaço e tempo: mais ao fundo, mais antigo.

Esse exemplo torna claro que não é um consenso que vai permitir uma relação mais simétrica. Não há um meio termo entre as duas concepções. É preciso aceitar a diferença. Como muito já se disse sobre os povos indígenas, eles têm muito mais facilidade em fazer isso do que nós. A abertura ao outro que caracteriza expressões dos pensamentos ameríndios ainda é um exercício difícil para nós cientistas.

A arqueologia é uma disciplina singular para esse exercício, em especial, na relação com tempo e espaço, já que o passado existe para nós também como materialidades do presente. No diálogo com os Wajãpi, eu comecei a perceber isto de uma forma muito mais evidente.

Da mesma forma que os cacos de cerâmica marcam as aldeias dos avós, que pertencem a um tempo histórico em que as genealogias são conhecidas, outras marcas apontam para os tempos ainda mais antigos. São marcas 
que dificilmente seriam interpretadas como tal por Arqueólogos (no sentido da "Ciência Normal"). As cores dos pássaros, o casco do jabuti, a estrutura dos galhos da Sumaúma são todas marcas de eventos do início do mundo. Se o Jacamim é preto, é porque foi o último a chegar na festa primordial, quando já não havia tintas para se pintar - ficou sem cor. Estas e outras marcas seguem atualizando as narrativas, seguem criando relações entre pessoas, vestígios e saberes.

É preciso aceitar a possibilidade de existência de outras temporalidades para aceitarmos a existência de outras arqueologias. Voltando à provocação de Roy Wagner (2010), que afirma que os nativos também são antropólogos, eu desloco isso para a arqueologia. Os Wajãpi, ao usarem marcas na construção de narrativas sobre o passado, estão praticando uma arqueologia. A maneira como esses conhecimentos são vividos pode não ser vista por eles como um conjunto, mas eu argumento que isso é uma arqueologia: a forma Wajãpi de construir narrativas sobre o passado a partir dos vestígios materiais.

\section{AGRADECIMENTOS}

À Fundação de Amparo à Pesquisa do Estado do Amapá (FAPEAP) e à Secretaria de Estado da Ciência e Tecnologia (SETEC-AP) pelo aporte financeiro recebido através do Edital 03/2011 Custeio Tese $\left(\mathrm{N}^{\circ}\right.$ Processo 35.000.059/2012-SETEC). A Dominique Tilkin Gallois pela generosidade em me apresentar aos Wajãpi e incentivar um aprendizado mútuo. Aos Wa- jãpi, em especial a turma de pesquisadores, pela partilha de conhecimentos e afetuosa hospitalidade que sempre recebi. A Marcia Bezerra e Flávio Leonel Abreu da Silveira, pelo apoio constante, sempre me instigando a refletir sobre os escritos e as práticas que lhes originaram.

\section{NOTAS}

${ }^{1}$ O Programa Wajãpi é desenvolvido em parceria entre a ONG Iepé (Instituto de Formação e Educação Indígena) e a associação indígena Apina (Conselho das Aldeias Wajãpi).

${ }^{2} \mathrm{O}$ registro da "Arte Kusiwa - Pintura Corporal e Arte Gráfica Wajãpi" foi realizado através do Processo IPHAN no 01450.000678/2002-27, tendo como proponente o Conselho das Aldeias Wajãpi Macapá/AP e o Museu do Índio - Funai. O processo foi aberto em 18/09/2002. $O$ pedido de registro foi aprovado na $38^{\mathrm{a}}$ reunião do conselho consultivo, em 11/12/2002. A inscrição no Livro de Registro das Formas de Expressão aconteceu em 20/12/2002, sendo este o primeiro registro do Livro. Estas informações foram obtidas no Dossiê publicado pelo IPHAN (Gallois 2006).

${ }^{3}$ Para uma reflexão recente sobre o papel da visão nos modos de conhecer dos Wajãpi, é possível consultar Oliveira (2012a).

${ }^{4}$ Fabíola Silva (2002) apresenta uma formulação semelhante elaborada pelos Asurini do Xingu para este mesmo tipo de vestígio.

\section{REFERÊNCIAS}

Bezerra, M. 2011. "As moedas dos índios": um estudo de caso sobre os significados do patrimônio arqueológico para os morado- 
res da Vila de Joanes, ilha do Marajó, Brasil. Boletim do MPEG 6 (1): 57-70

2013. Os sentidos contemporâneos das coisas dos passados: reflexões a partir da Amazônia. Revista de Arqueologia Pública 7107-122

Bruchac, M.M., S.M. Hart, \& H.M. Wobst (Eds.). 2010. Indigenous archaeologies: a reader on decolonization. Walnut Creek: Left Coast Press.

Bueno, L., e J. S. Machado (Eds.). 2013. Revista de Arqueologia 26 (1).

Castañeda, Q.E., \& C. N. Matthews (Eds.). 2008. Ethnographic Archaeologies. Reflections on Stakeholders and Archaeological Practices. Lanham/ Plymouth: Altamira Press.

Colwell-Chanthaphonh, C., \& T. J. Fergunson (Eds.). 2008. Collaboration in Archaeological Practice: Engaging Descendant Communities. Plymouth: Altamira Press.

Eremites de Oliveira, J., \& L.M. Pereira. 2010. Reconhecimento de territórios indígenas e quilombolas em Mato Grosso do Sul: desafios para a antropologia social e a arqueologia em ambiente colonialista, in Arqueologia, etnologia e etno-história em Iberoamérica: fronteiras, cosmologia, antropologia em aplicaşão. Editado por R.L.S. Aguiar, J. Eremites de Oliveira, \& L. M. Pereira, pp. 185208. Dourados: Editora da UFGD.

Gallois, D.T. 1994. Mairi Revisitada: A reintegração da Fortalez̧a de Macapá na tradição oral dos Waiäpi. São Paulo: NHII/ USP/ FAPESP.

1988. O movimento na cosmologia Wajāpi: Criação, expansão e transformação do universo. Tese de Doutorado. Faculdade de Filosofia, Letras e Ciências Humanas, Universidade de São Paulo, São Paulo.

2001. Essa incansável tradução entrevista com Dominique Tilkin Gallois. Sexta-Feira: Antropologia, Artes \& Humanidades 6: 1-10.
2006. Expressão gráfica e oralidade entre os Wajāpi do Amapá. Dossiê IPHAN 2 $\{$ Wajāpi $\}$. Rio de Janeiro: IPHAN/ MinC.

2011. Terra Indigena Wajäpi: da demarcação às experiências de gestão territorial. São Paulo: Iepé.

2012. Donos, detentores e usuários da arte gráfica Kusiwa. Revista de Antropologia 55 (1): 19-49.

Gallois, D.T. et al. 2013. Saberes Wajãpi: Formação de pesquisadores e valorização dos registros etnográficos indígenas, in Otros saberes: collaborative research on indigenous and Afro-descendant cultural politics. Editado por C. R. Hale, \& L. Stephen, pp. 49-75. New Mexico: School for Advanced Research Press.

Gnecco, C. 2008. Modernity and politics in Colombian archaeology, in Handbook of South American Archaeology. Editado por H. Silverman \& W. H. Isbell, pp. 1103-1113. New York: Springer.

2009. Caminos de la arqueología: de la violencia epistêmica a la relacionalidad. Boletim do Mus Par Em Goeldi. Ciências Humanas 4(1): 15-26.

2012. "Escavando" arqueologias alternativas. Revista de Arqueologia SAB 25(2):08-22.

Gnecco, C., \& P. A. Rocababo (Eds.). 2010. Pueblos indigenas y arqueología en América Latina. Bogotá: Fundación de Investigaciones Arqueológicas Nacionales/ Banco de la República/ CESO, Faculdad de Ciencias Sociales, Universidad de los Andes.

Gonzalo, A.H. 2006. Arqueología y Globalizatión. El problema de la definición del "otro" en la Postmodernidad. Complutum $17: 221-234$

Green, L.F., D.R. Green, \& E.G. Neves. 2003. Indigenous Knowledge and Archaeological Science: The Challenges of Public 
Archaeology in the Reserva Uaça. Journal of Social Archaeology 3 (3):365-397

Grenand, F. 2009. Nomear seu universo: Por quê? Como? Alguns exemplos entre as sociedades amazônicas. Cadernos de Campo 18:1-354

Grenand, P., D.T. Gallois, \& F. Grenand. 2009. Un peuple Tupi-Guarani: les Wayãpi, in Encyclopédies palikur, wayana \& wayäpi. Langue, milieu et histoire. Editado por F. Grenand, pp: 86-115. Orleans: Presses universitaires d'Orleans.

Grenand, P., \& F. Grenand. 2002. Em busca da aliança impossível. Os Waiãpi do norte e seus brancos, in Pacificando o branco: cosmologias do contato no norte-amazônico. Editado por B. Albert, \& A. R. Ramos, pp. 145-178. São Paulo: Editora UNESP.

Haber, A. 2009. Localizing the Global: A Framework for Discussing WAC's Problems Promise. Present Pasts $1: 1-6$

Haber, A., \& C. Gnecco. 2007. Virtual Forum: Archaeology and Decolonization. Archaeologies: Journal of the World Archaeological Congress 3 (3): 390-412

Hamilakis, Y., \& A. Anagnostopoulos (Eds.). 2009. Archaeological Ethnographies. Cambridge: Maney Publishing.

Hamilakis, Y. 2008. Decolonizing Greek archaeology: indigenous archaeologies, modernist archaeology and the post-colonial critique. Athens 3:1-15.

Instituto do Patrimônio Histórico e Artístico Nacional. 2002. Certidão do Livro de Registro das Formas de Expressão. Arte Kusiwa - Pintura Corporal e Arte Gráfica Wajāpi. Brasília: IPHAN/ MinC.

Kuhn, T. S. 2003. A Estrutura das Revolucões Cientificas. São Paulo: Perspectiva.

Latour, B. 2005. Reassembling the Social. An Introduction to Actor-Network-Theory. Oxford: Oxford University Press.
1994 [1991]. Jamais fomos modernos. Rio de Janeiro: Editora 34.

Mortensen, L., \& J. Hollowell (Eds.). 2009. Ethnographies and archaeologies: iterations of the past. Gainesville: University Press of Florida.

Nicholas, G. 2005. The persistence of memory; the politics of desire: archaeological impacts on Abroiginal peoples and ther response, in Indigenous Archaeologies: Decolonizing theory and practice. Editado por C. Smith, \& H. M. Wobst (e-book). Abingdon/ New York: Routledge.

Oliveira, J.C. 2006. Classificações em Cena: Algumas Formas de Classificação das Plantas Cultivadas pelos Wajäpi do Amapari (AP). Dissertação de Mestrado. Departamento de Antropologia, Faculdade de Filosofia, Letras e Ciências Humanas, Universidade de São Paulo, São Paulo.

. 2012a. "Vocês sabem porque vocês viram!": reflexão sobre modos de autoridade do conhecimento. Revista de Antropologia 55(1):51-74.

.2012b. Entre Plantas e Palavras: Modos de Constituição de Saberes entre os Wajäpi (AP). Tese de Doutorado, Departamento de Antropologia, Universidade de São Paulo, Brasil.

Pesquisadores Wajãpi. 2012. Formação de Pesquisadores Wajãpi. Folder de divulgação. São Paulo, Macapá: Apina, Iepé.

Phillips, C., \& H. Allen (Eds.). 2010. Bridging the Divide. Indigenous Communities and $A r-$ chaeology into the 21st Century. Walnut Creek: Left Coast Press.

Silva, F.A. 2011. Patrimônio Arqueológico em Terras Indígenas: Considerações sobre o Tema no Brasil, in Patrimônio cultural no Brasil e na Argentina: estudos de caso. Editado por L.M. Ferreira, M.L.M. Ferreira, \& M.B. Rotman, pp. 189-214. São Paulo: Annablume. 
2002. Mito e Arqueologia: A interpretação dos Asurini do Xingu sobre os vestígios arqueológicos encontrados no Parque Indígena Kuatinemu - Pará. Horizontes Antropológicos. 8. (18): 175-187

Silva, F.A., E. Bespalez, \& F.F. Stuchi. 2011. Arqueologia Colaborativa na Amazônia: Terra Indígena Kuatinemu, Rio Xingu, Pará. Amazônica 3(1):32-59

Smith, C., \& H.M. Wobst (Eds.). 2005. Indigenous Archaeologies: Decolonizing theory and practice. Abingdon/ New York: Routledge.

UNESCO. 2012. Representative List of the Intangible Cultural Heritage of Humanity. Disponível em http:// www.unesco.org/culture/ich/index. php?lg $=$ en\&pg $=00011 \&$ RL $=00049$. Acesso em $05 / 05 / 2012$.

Viveiros de Castro, E. 2002. Perspectivismo e multinaturalismo na América indígena, in $A$ inconstancia da alma selvagem - $e$ outros ensaios de antropologia. Editado por E. Viveiros de Castro, pp. 347-399. São Paulo: Cosac \& Naify.

Wagner, R. 2010 [1975]. A invenção da cultura. São Paulo: Cosac Naify.

Recebido em 07/04/2014

Aprovado em 15/07/2014 